\title{
Individualidade em sentido moral e
}

\author{
Individuality in moral sense and Eternal Justice
}

\section{Rogério Moreira Orrutea Filho'}

Resumo: O presente artigo tem como ponto de partida um outro trabalho, de nossa própria autoria, pelo qual buscou-se demonstrar a necessidade de se estabelecer, na filosofia de Schopenhauer, a distinção entre a individualidade em sentido moral e a individuação em sentido corpóreo. Naquele artigo, reconhecemos que nossa abordagem encontrou significativo obstáculo na tese schopenhaueriana da Justiça Eterna. Com o objetivo de remover este obstáculo, tentaremos agora demonstrar que a Justiça Eterna é, em última instância, incompatível com elementos mais fundamentais da filosofia de Schopenhauer.

Palavras-chave: Vontade; Caráter; Justiça; Ética; Individualidade

Abstract: This article has as its starting point another work from our own authorship, where we established the distinction between individuality in moral sense and individuation in corporeal sense, inside Schopenhauer's philosophy. In that article, we admitted that our approach had found an obstacle in Schopenhauerian thesis of Eternal Justice. In order to remove such obstacle, we will now try to demonstrate that the Eternal Justice is incompatible with more fundamental elements of Schopenhauer's philosophy.

Keywords: Will; Character; Justice; Ethics; Individuality

\section{Introdução}

Em artigo apresentado em 2013 na Universidade Estadual de Londrina (UEL), durante o $V$ Congresso Nacional de Filosofia Contemporânea, busquei esclarecer um problema teórico que julgo de importância capital na filosofia schopenhaueriana: a individualidade moral como contraposta à mera individuação corpórea ${ }^{1}$. Aquilo que talvez poderíamos chamar de estatuto ontológico da individualidade humana, e que constitui uma simples "obviedade" para a consciência do vulgo, conduz-nos a questões extremamente problemáticas no contexto do "pensamento único" do autor de $\mathrm{O}$ mundo como vontade e representação. Pois ninguém poderia duvidar da existência de sua própria individualidade; porém, de acordo com as conclusões de Schopenhauer, toda forma de individualidade é, em um sentido bastante forte, uma "ilusão" condicionada pelo "Véu de Maia", uma mera representação submetida a formas apriorísticas que constituem a consciência do sujeito e nada mais. No âmbito da coisa em si mesma - isto é, naquilo que restaria do mundo quando subtraído de toda forma de representação - haveria apenas a vontade una e indivisa em todo e qualquer

\footnotetext{
Mestre em filosofia pela UEL e professor da Faculdade Dom Bosco. rogeriomofilho@gmail.com

Este trabalho fora publicado sob o título de "Sobre a distinção entre individualidade moral e individuação corpórea em Schopenhauer", na coletânea Schopenhauer: metafísica e moral, organizada por Aguinaldo Pavão, Charles Feldhaus e José Fernandes Weber (São Paulo: DWW Editorial, 2014).
} 
fenômeno. Portanto, no que diz respeito à individualidade humana, parece haver uma forte contradição entre aquilo que a filosofia de Schopenhauer ensina e aquilo que vulgarmente sentimos em nossa consciência.

Cremos que toda genuína atividade filosófica se caracteriza por aquela tarefa que Husserl consciente e explicitamente impôs a si mesmo, e que consiste em desmanchar as chamadas "obviedades" que acometem a consciência vulgar, isto é, "na suspensão de validades natural-ingênuas" ${ }^{2}$, uma vez que "toda evidência é o nome de um problema" . Se Schopenhauer alcançou os limites da evidência tal como exigido pela epoché husserliana, isto pode ser debatido ${ }^{4}$. Mas não seria razoável duvidar que Schopenhauer contribui imensamente para "uma modificação temática do mundo, que rompe com a normalidade do viver imerso" ${ }^{5}$, relativamente ao significado ou extensão, em termos mais substanciais, da individualidade humana.

Em nosso trabalho citado, concluímos que, em Schopenhauer, devemos trabalhar com duas noções diversas de "individualidade": uma exclusivamente aplicada à nossa dimensão corpórea, e que se expressaria apenas no âmbito de nossas representações empíricas, condicionadas pelo espaço, tempo e causalidade; e uma de alcance metafísico e, consequentemente, rica em significado moral. Esta última categoria de individualidade, embora não deixasse de ser, estritamente falando, uma representação ou fenômeno, no entanto seria uma representação de raiz metafísica, um fenômeno imediato da coisa-emsi, que se manifesta no tempo sem ser por ele fundamentada, despossuída de contornos espaciais e independente da causalidade, porque é livre ${ }^{6}$. Nosso caráter inteligível seria a expressão de nossa individualidade em sentido moral.

De acordo com os resultados por nós obtidos, questões suscitadas pela Ética de Schopenhauer, tais como liberdade moral e direito à propriedade, só fariam pleno sentido se pressupormos a referida distinção entre individuação corpórea e individualidade moral ${ }^{7}$. Por outro lado, tivemos de reconhecer que há um ponto na filosofia de Schopenhauer que parece conflitar drasticamente com nosso posicionamento: o problema da Justiça Eterna. Naquela oportunidade, dissemos que a própria noção de Justiça Eterna, tal como apresentada por Schopenhauer, seria extremamente complicada por si só, em função de seu aspecto extremamente contraintuitivo e confuso, de sorte que a resolução deste conflito demandaria um trabalho específico ${ }^{8}$. Este artigo pretende ser este trabalho ${ }^{9}$.

\footnotetext{
HUSSERL, A crise das ciências europeias e a fenomenologia transcendental, p. 110.

HUSSERL, A crise das ciências europeias e a fenomenologia transcendental, p. 154.

${ }^{4}$ As supostas inconsistências que Husserl aponta em Locke e Kant, e que teriam conduzido os dois filósofos a fracassar em seu empreendimento de alcançar uma fundamentação última (HUSSERL, A crise das ciências europeias, p. 68-80), poderiam ser facilmente acusadas em Schopenhauer. Além disso, a crítica ainda mais contundente que Husserl faz ao "idealismo psicológico" (HUSSERL, A crise das ciências europeias, p. 55), consistente em compreender a esfera subjetiva sob a influência de conceitos "fisicalistas" ou objetivos. Schopenhauer cairia neste tipo de inconsistência sempre que considera o cérebro como o órgão no qual residem nossas regras subjetivas constituintes de nossas representações. Ao depositar a fonte do transcendental no cérebro, que é corpóreo, Schopenhauer inadvertidamente "corporiza" o transcendental.

5 HUSSERL, A crise das ciências europeias e a fenomenologia transcendental, p. 117.

6 ORRUTEA FILHO, Sobre a distinção entre individualidade moral e individuação corpórea em Schopenhauer, p. 185-186.

ORRUTEA FILHO, Sobre a distinção entre individualidade moral e individuação corpórea em Schopenhauer, p. 176-179.

8 ORRUTEA FILHO, Sobre a distinção entre individualidade moral e individuação corpórea em Schopenhauer, p. 185

9 Não posso deixar de mencionar o fato de que este artigo fora, em grande parte, inspirado pela conferência "Liberdade e responsabilidade moral: o fracasso de Schopenhauer", apresentada por Aguinaldo Pavão, no I Congresso do Núcleo de Pesquisa Schopenhauer-Nietzsche: 200 anos de O mundo como vontade e representação, realizado no campus da Universidade de Londrina em julho de 2018. Nesta brilhante conferência, o autor demonstrou incidentalmente como a tese da Justiça Eterna conduz a resultados embaraçosos no âmbito moral. E como a tese da Justiça Eterna seria, na opinião de Pavão, um sucedâneo necessário das bases mais fundamentais da filosofia de Schopenhauer, então semelhante embaraço seria intrínseco ao seu "pensamento único", o que denunciaria seu "fracasso". O grande objetivo do presente trabalho é justamente o de mostrar que a tese da Justiça Eterna não é intrínseca à filosofia de Schopenhauer, na medida em que seus resultados contradizem elementos essenciais de seu filosofar.
} 


\section{Um breve resumo das evidências que conduzem ao reconhecimento da individualidade em sentido moral na filosofia de Schopenhauer}

Antes de explorar diretamente seu conflito com a "justiça eterna", faremos aqui uma recapitulação dos pontos mais essenciais de nossos argumentos já apresentados em trabalho anterior (Sobre a distinção entre individualidade moral e individuação corpórea), e que pretendem demonstrar a necessidade de se admitir, na filosofia de Schopenhauer, a ideia de um sentido de individualidade que não se restringe ao universo das meras representações.

\section{A individualidade condicionada pelo espaço e tempo: a individuação corpórea}

Um dos traços mais característicos do sistema filosófico de Arthur Schopenhauer é a afirmação de acordo com a qual a totalidade do mundo apresenta-se sob dupla perspectiva: ora como representação, exterior ao sujeito que conhece, e ora como vontade, revelada a partir da experiência interna do mesmo sujeito. O mundo como representação seria "a parência”, mero fenômeno constituído pelo aparato cognitivo do sujeito, na medida em que está submetido às formas a priori daquele, formas estas que são espaço, tempo e causalidade. Da união da ação das formas intuitivas do espaço e do tempo, ter-se-ia o principium individuationis (princípio da individuação), verdadeiro sustentáculo intelectual da diversidade formal, pluralidade ou individualidade dos entes (W I, §23, p. 171). A isso se contrapõe o mundo como vontade ou coisa-em-si, o qual, nesta condição, não está submetido ao principio individuationis.

Se o princípio de individuação sustenta-se no espaço e no tempo, isso só pode significar que as diferenças ou pluralidade dos entes que compõem o mundo como representação se manifestam apenas pela coexistência com outros corpos, e porque seus atos, estados e movimentos se sucedem em diferentes momentos. A coexistência ou justaposição pressupõem a intuição espacial, pois apenas mediante o espaço podemos conceber o fato de algo estar um ao lado do outro (neben einander). Da mesma maneira, a sucessão de diferentes estados em uma mesma coisa também pressupõe uma forma intuitiva, a intuição de tempo, pois apenas mediante o tempo podemos conceber o fato de algo ser um após o outro (nach einander) (G, §18, p. 44 e ss.). Em suma, a individualidade física supõe, por parte do corpo individual, a ocupação de um diferente ponto do espaço, ou a sucessão de seus estados e movimentos em diferentes momentos do tempo. Logo, sem espaço e tempo, nenhuma individualização corpórea e objetiva é possível.

Mas, conforme exaustivas declarações de Schopenhauer, tempo e espaço são condições a priori de intuição, e, assim, fornecem apenas representações. Por essa razão, propriedades espaciais e temporais não atingem a coisa em si mesma, a vontade, a qual, como aquilo que está além de nossas representações e sobre a qual nossas formas intuitivas não se aplicam, precisa estar fora do espaço e do tempo. E se está fora do espaço e do tempo, vale dizer, para além do princípio de individuação, então a vontade deve ser una e indivisa em todo e qualquer fenômeno, pois apenas aquilo que se submete ao citado princípio pode ser individual ou plural. Mas então uma vontade individual seria simples representação, ilusão, aparência. Assim, num primeiro momento, toda a pluralidade fenomênica que aparece no mundo como representação seria reduzida a uma unidade volitiva no mundo como vontade, a qual, enquanto coisa-em-si, seria una, indivisa e indiferente em todo e qualquer fenômeno. 


\title{
Da raiz metafísica do caráter individual
}

Porém, esta última afirmação simplesmente não parece coincidir com a realidade. Pois do fato de que um corpo se distingue do outro em razão de pressupostos espaçotemporais, não se segue que a vontade manifestada naquele corpo se distingue da vontade manifestada neste corpo em razão dos mesmos pressupostos. Primeiramente, uma vontade sequer possui propriedades espaciais. Todavia, ela ainda se manifesta no tempo; porém, o que distingue uma vontade individual da outra não é o fato de que ela se manifesta em diferentes momentos, mas a distinção é de ordem característica. Isso significa que este homem não se difere daquele outro homem apenas por causa de seus contornos espaciais e da sucessão de seus movimentos corpóreos em diferentes momentos do tempo, mas, sobretudo, ambos diferem entre si porque cada um é portador de uma constituição anímica toda particular e inconfundível: ambos manifestam uma evidente distinção em suas inclinações, desejos, ações, reações, gostos, preferências, finalidades, aversões, etc. Em suma, suas respectivas vontades se expressam de diferentes modos, e, assim, podemos dizer que cada um possui seu próprio caráter, pois o caráter é justamente a expressão da uniformidade de nossas ações ou manifestações volitivas, ou, como o próprio Schopenhauer define, "esta qualidade (Beschaffenheit) especialmente e individualmente determinada da vontade, em virtude da qual sua reação diante do mesmo motivo é diferente em cada homem” (E, III, p. 87). Aqui, convém traçar algumas considerações sobre o caráter humano e seus atributos.

De acordo com Schopenhauer, o caráter pode ser visto sob duas perspectivas: empírica e inteligível. O caráter empírico é simplesmente a imagem fenomênica do caráter inteligível, vale dizer, ele é a manifestação do caráter inteligível quando sobmetido ao tempo, forma a priori de nossa intuição (E, V, p. 137). Pode-se dizer que o caráter empírico é a imagem fragmentada do caráter inteligível, ou ainda: o caráter empírico refere-se a uma revelação gradativa que adquirimos de nosso próprio caráter inteligível ao longo de nossa experiência. Conhecemos através do tempo - por meio do caráter empírico - aquilo que está fora do tempo - nosso caráter inteligível. Daí Schopenhauer afirmar que somente por meio da experiência podemos conhecer não apenas os outros, mas também a nós mesmos (E, III, p. 87). Conhecemos através do tempo - por meio do caráter empírico - aquilo que está fora do tempo - nosso caráter inteligível. Daí Schopenhauer afirmar que somente por meio da experiência podemos conhecer não apenas os outros, mas também a nós mesmos (E, III, p. 87). Contudo, um outro atributo de nosso caráter, conforme já foi falado, é a sua constância, atributo este que Schopenhauer define nos seguintes termos:

\begin{abstract}
O caráter permanece o mesmo, ao longo de toda a vida. Sob os diversos invólucros de nossos anos, de nossas relações, mesmo de nossos conhecimentos e opiniões, encontra-se, como um caranguejo em sua casca, o homem enquanto tal, idêntico, totalmente imutável e sempre o mesmo. Apenas na direção e matéria o seu caráter sofre as modificações aparentes, que são consequências da diferença de idade e de suas necessidades. O homem jamais muda: tal como ele agiu em uma determinada situação, voltará a agir sob circunstâncias idênticas (porém, para isso também é preciso que se tenha o conhecimento correto destas circunstâncias) (E, III, p. 87).
\end{abstract}

Por outro lado, segundo Schopenhauer, o tempo é a "possibilidade de determinações contrárias em uma mesma coisa” (G, $\S 18$, p. 44), vale dizer, o tempo se refere a mudanças. Mas nosso caráter contrasta com a ação do tempo, uma vez que o conjunto de suas manifestações, embora fragmentadas, indicam uma constância e imutabilidade. Logo, ele não pode estar submetido ao tempo, embora se manifeste no tempo. A partir disso já se vê que "manifestarse no tempo" não se confunde com "estar submetido ao tempo".

$\mathrm{Da}$ constância que nosso caráter empírico revela gradativamente - porque se 
manifesta no tempo - segue-se a necessária pressuposição de uma dimensão inteligível do mesmo, inteiramente atemporal. Assim, tem-se aquilo que Schopenhauer chama de caráter inteligível, já mencionado. Este, por sua vez, deve ser considerado como um ato de vontade extratemporal (W I, §55, p. 364), e, uma vez que a primeira das características do caráter humano é justamente a de que ele é "individual” (E, III, p. 87), então pode-se acrescentar: o caráter inteligível deve ser considerado como um ato extratemporal da nossa própria vontade individual, o que nos leva à identificação, numa esfera transcendental, entre querer e $\operatorname{ser}^{10}$, pois aquilo que somos - isto é, nosso caráter individual - já é aquilo que queremos extratemporalmente. Isso é o mesmo que dizer que a natureza última de cada indivíduo, que é sua própria vontade, não está submetida à autoridade do tempo, e nisso consiste sua liberdade moral. Em toda a obra de Schopenhauer, abundam trechos neste sentido.

Assim, ele escreve no Mundo como vontade e representação (W I, §55, p. 368) que "cada homem é aquilo que é através de sua vontade", e, consequentemente, que o homem "é a sua própria obra antes de todo conhecimento" (grifo nosso).

Em Sobre os dois problemas fundamentais da ética, no pequeno e significativo apêndice acrescentado ao final de Sobre a liberdade da vontade humana, ele afirma que cometeríamos injustiça ao condenarmos um criminoso, se "seu caráter moral não fosse sua própria obra, seu ato inteligível” (grifo nosso).

Em Parerga e paralipomena, nos "fragmentos sobre a história da filosofia", Schopenhauer escreve:

Liberdade moral e responsabilidade, ou imputabilidade, simplesmente pressupõem asseidade (Aseität). As ações sempre são produzidas, com necessidade, a partir do caráter - i.e., a partir da qualidade (Beschaffenheit) própria e, assim, imutável de um ser - sob a influência e de acordo com a determinação dos motivos. Portanto, devendo ser ele responsável, o mesmo precisa existir originariamente e a partir de sua própria plenitude de poderes: ele, de acordo com sua existentia e essentia, precisa ser sua própria obra e o autor de si mesmo, se ele deve ser o verdadeiro autor de suas ações (P I, p. 141).

Por todas estas razões, Schopenhauer conclui expressamente que a individualidade humana não pode ser considerada apenas um simples produto ou artifício do princípio de individuação. Assim, escreve ele nos suplementos ao Mundo como vontade e representação:

Entretanto, a individualidade (Individualität) é inerente, em primeiro lugar, ao intelecto, o qual, refletindo o fenômeno, faz parte do fenômeno que tem por forma o principium individuationis. Mas ela é inerente também à vontade, na medida em que o caráter é individual (W II, cap. 48, p. 713).

E em outro trecho, na obra Parerga und Paralipomena, Schopenhauer se pronuncia no mesmo sentido, com o acréscimo de que dessa vez destaca a mistério da individualidade humana, para a qual, em última instância, sua própria filosofia não pode oferecer uma explicação completa e exaustiva, limitando-se, assim, ao reconhecimento de que, apesar de misteriosa - justamente porque não pode ser considerada mera determinação do princípio de individuação, encontrando-se também para além dos limites do princípio de razão -, nem por isso sua existência pode ser contestada:

Disso agora se segue que a individualidade (Individualität) não se baseia apenas sobre o principio individuationis, e, por isso, não é simplesmente mero fenômeno; mas que ela se enraíza na coisa em si, na vontade do indivíduo: pois o seu próprio caráter é individual. Mas quão profundas são suas raízes, isso é uma questão cuja resposta eu não posso dar (P II, §116, p. 248).

\footnotetext{
${ }^{10}$ Esta identificação entre querer e ser pode ser atestada na seguinte fórmula: "pois eu quero de acordo com aquilo que sou: por isso, eu devo ser de acordo com aquilo que quero" (N, p. 338).
} 
Podemos reforçar ainda mais esta assertiva por meio de trechos retirados dos Pandectae II, que foram manuscritos pessoais datados de 1834, onde Schopenhauer reconhece que as "distinções éticas" dos caracteres são "imediatamente" produzidas a partir da vontade, e não guardam relação com o princípio de individuação. Este produziria apenas uma "distinção quantitativa”, enquanto que as distinções éticas seriam "qualitativas":

\begin{abstract}
Eu tenho demonstrado o espaço e tempo como principium individuationis, uma vez que a pluralidade daquilo que é homogêneo é possível somente através dele. Mas aquilo que é plural, também é heterogêneo; a pluralidade e distinção não é apenas quantitativa, mas também qualitativa. [...]

A distinção intelectual tem seu fundamento imediato no cérebro e sistema nervoso, e, por isso, é algo menos obscuro [...].

Mas a distinção ética parece resultar imediatamente (unmittelbar) da vontade. A princípio, ela também não seria atemporal, uma vez que intelecto e vontade são associados somente no indivíduo. A vontade é atemporal, eterna; e o caráter é inato, portanto, nascido daquela eternidade; consequentemente, não pode ser explicado a partir de nada que é imanente.

Talvez, depois de mim, alguém elucide e esclareça este abismo (HN, Pandectae II, §97, p. 193).
\end{abstract}

No mesmo sentido, Schopenhauer baseia a "identidade pessoal" de cada indivíduo sobre "a vontade idêntica e o caráter imutável da mesma”, e não sobre o corpo individualizado, uma vez que ele, tanto na sua forma quanto na sua matéria, sofre as alterações proporcionadas pelo tempo (W II, cap. 19, p. 278 e ss.). Consequentemente, evidencia-se aqui a distinção entre individualidade pessoal ou moral, baseada na vontade ou caráter do indivíduo, e a mera individualidade corpórea, baseada nas formas de espaço e tempo, isto é, no princípio de individuação.

Portanto, pode-se dizer que a raiz de nossa individualidade ou particularidade moral - para se diferenciar aqui da mera individualidade corpórea - encontra-se no âmago mais profundo de nosso ser, isto é, em nossa vontade. Essencialmente, somos indivíduos porque nossa vontade é individual. Por esse motivo, nossa individualidade moral não se deixa reduzir a meras relações de espaço, tempo e causalidade, e, assim, não é simples representação ou fenômeno.

No trabalho onde expomos estas noções, concluímos que por estes motivos teríamos reinterpretar o sistema filosófico de Schopenhauer não mais em termos bidimensionais, mas em termos tridimensionais, para acomodarmos a individualidade moral do homem, de raiz metafísica, em uma dimensão intermediária, localizada (e aqui nos expressamos em termos bastante metafóricos) entre as extremidades da coisa-em-si una e indivisa e aquilo que passaríamos a chamar, em sentido mais técnico, de "simples fenômenos", constituídos pelas formas do princípio de razão e pelo princípio de individuação. Esta dimensão intermediária seria a dos "fenômenos imediatos da vontade"11.

\title{
O porquê da nomenclatura "individualidade moral"
}

Deve-se frisar que tais considerações concernentes à diferença entre individualidade moral e corpórea não são inteiramente novas. Alain Roger ${ }^{12}$ afirma que devemos distinguir individualidade metafísica de individuação física, e cita M. Piclin e S. Reinach como estudiosos que já haviam diagnosticado o mesmo problema.

A novidade em nosso trabalho já citado várias vezes neste artigo se encontra no fato de que o mesmo enfatiza que a individualidade metafísica é sobretudo de natureza moral,

\footnotetext{
${ }^{11}$ ORRUTEA FILHO, Sobre a distinção entre individualidade moral e individuação corpórea em Schopenhauer, p. 186.

12 ROGER, Atualidade de Schopenhauer, LXXI.
} 
pois entendemos que ela é um pressuposto necessário para que a Ética de Schopenhauer faça sentido. Pois se e a individualidade é mero produto do princípio de individuação, então ela é vazia de significado ético, uma vez que seria então pura representação, e o mundo como representação, apartado do mundo como vontade, é inteiramente neutro do ponto de vista moral. A condição mínima de qualquer apreciação moral é, como diz Brian Magee, a "interface" entre o mundo fenomênico e o noumênico ${ }^{13}$. Um elemento da esfera da coisa-em-si precisa se mesclar na representação, para que esta adquira alguma significação moral, pois se abstraímos da representação a influência da vontade, então nada restaria senão um mundo inteiramente mecânico e sem vida. Afinal, como seria possível avaliar eticamente o movimento de um corpo, inteiramente determinado segundo o princípio da causalidade, e que fosse diferente de um outro corpo - sobre o qual ele produzisse um determinado efeito - apenas pelo fato de que ocupa um diferente ponto no espaço? A análise inteiramente subordinada às formas a priori, sem qualquer referência às nossas manifestações volitivas, conduz-nos à neutralidade científica, mas não ao universo dos valores morais. O mundo como representação, apartado do mundo como vontade, é o mundo da ciência amoral.

Nestes termos, é possível constatar que, a Ética de Schopenhauer, se articulada no interior de um sistema que reduz a individualidade à mera representação, restaria fortemente prejudicada, e talvez destituída de sentido. Por consequência disso, não poderíamos justificar, por exemplo, a argumento de Schopenhauer que fundamenta o direito natural à propriedade privada ${ }^{14}$.

Outro importante ponto da Ética de Schopenhauer que pressupõe uma individualidade de raiz metafísica, é sua justificação da liberdade moral. Se a liberdade, fonte de nosso senso de responsabilidade pessoal por nossa própria essência, for atribuível apenas àquela obscura entidade metafísica "una e indivisa" em todos os fenômenos, então somos forçados a concordar com Ferraz ao concluir que "na teoria de Schopenhauer, a liberdade moral paga o preço de deixar de ser uma liberdade humana e individual”' ${ }^{15}$. Nestes termos, Janaway (2003, p. 117) também teria total razão ao afirmar que

[...] eu pareço desaparecer do mundo-em-si. A coisa-em-si não se divide em indivíduos - uma alegação essencial em toda a filosofia de Schopenhauer. "Minha vontade como coisa-em-si", meu caráter inteligível, não deve ser separado do mundo como um todo; desse modo, é difícil ver como posso ser julgado responsável por aquilo "que sou propriamente" 16 .

Acreditamos que só podemos contornar esta inconsistência acusada por Janaway se supormos uma distinção entre a individualidade moral - referente ao caráter inteligível individual - e a individualidade corpórea e a consequente consciência individual que ela acarreta. Pois o eu é condicionado pelo intelecto, e, consequentemente, é condicionado por um simples fenômeno submetido às formas do princípio de razão (pois o intelecto se situa no cérebro, portanto, no corpo). Por isso, ao discursar sobre a questão da identidade pessoal - baseada na "vontade idêntica e no caráter imutável da mesma”, conforme já abordado neste trabalho - Schopenhauer escreve que "o homem consiste no coração, não na cabeça. Porém, em consequência de nossas relações com o mundo exterior, nós somos acostumados a considerar como nosso em si propriamente dito o sujeito do

\footnotetext{
13 MAGEE, The philosophy of Schopenhauer, p. 217.

14 Minha justificativa para esta asserção encontra no artigo Sobre a distinção entre individualidade moral e individuação corpórea em Schopenhauer.

${ }^{15}$ FERRAZ, Liberdade e responsabilidade moral em Schopenhauer, p. 152.

16 JANAWAY, Schopenhauer, p. 117.
} 
conhecer, o eu cognoscente" (W II, cap. 19, p. 279) ${ }^{17}$.

Porém, em nosso trabalho que serviu de premissa para o presente artigo, deixamos claro que a tese schopenhaueriana da "justiça eterna" representaria um obstáculo à interpretação que oferecemos. Passemos agora à consideração deste ponto específico, primeiro por meio de uma pequena exposição dos conceitos centrais que sustentam a tese da Justiça Eterna, para só depois proceder a uma análise crítica sobre a mesma.

\section{A tese da Justiça Eterna}

No $\$ 63$ de O mundo como vontade e representação, Schopenhauer afirma que a Justiça Eterna se diferencia da Justiça Temporal na medida em que a primeira não é retaliadora, pois retaliação demanda tempo, e a Justiça Eterna não está no tempo, porque não pertence à ordem dos fenômenos. Na verdade, "a punição na justiça eterna tem de ser tão ligada à injúria que ambas se tornam unas” (W I, §63, p. 448). Esta asserção se justifica pela tese que afirma a identidade metafísica entre todos os seres que compõem o mundo dos fenômenos. Se as diferenças que caracterizam nossa singularidade são meras representações, então em si (isto é, para além das representações) somos uma coisa só. Nestas condições, toda injúria provocada conduz, simultaneamente, à própria punição, uma vez que a pessoa do agressor e a pessoa da vítima se distinguem apenas na representação, sendo em si mesmos idênticos. Consequentemente, o "atormentador e o atormentado são unos. O primeiro erra ao acreditar que não participa do tormento, o segundo ao acreditar que não participa da culpa” (W I, §63, p. 452).

Neste contexto, a vítima é tão culpada quanto o agressor, uma vez que a vontade do agressor é, em última instância, também a vontade da própria vítima. Aliás, todos somos igualmente responsáveis pelas penúrias e sofrimentos que nos acompanham neste mundo, ainda que jamais tenhamos concorrido para qualquer mal, pois nossa inocência seria tão aparente quanto nossa individualidade, restrita ao mundo como representação. Aliás, pela ideia de Justiça Eterna, toda inocência é representação; a única realidade é a culpa universal. No em si, no âmbito do ens realissimum, prevalece a identidade metafísica da "Vontade", e o mundo é tal como queremos que ele seja, pois este mundo é nossa Vontade:

Em conformidade com isso, todo ser assume com extrema justiça a existência
em geral, logo, a existência da sua espécie e a da própria individualidade,
precisamente como é e nas circunstâncias dadas em um mundo tal como é,
ou seja, regido pelo acaso e o erro (...) em tudo o que acontece ou que pode
acontecer a cada um, a justiça sempre lhe é feita, pois sua é a Vontade. Tal
qual a Vontade é, é o mundo (W I, $\$ 63$, p. 449$)$.

De acordo com o trecho acima transcrito, fica claro que a tese da Justiça Eterna contradiz a justiça temporal, baseada na proporcionalidade harmônica no ato de afirmação individual da vontade de cada um, pois a justiça é negação da injustiça, e esta se define pela afirmação da "vontade para além do próprio corpo mediante a negação da vontade que aparece no corpo alheio” (W I, §62, p. 429). Dito de modo mais simples, a justiça temporal pressupõe individualidade, enquanto que a Justiça Eterna, nas palavras de Raymond Marcin, "prescinde da própria individualidade"18.

\footnotetext{
${ }^{17}$ Devemos ainda acrescentar que, adotando nosso ponto de vista em recente palestra realizada durante um dos encontros do núcleo de estudos Schopenhauer-Nietzsche da UEL, Ednilson Antoniassi concluiu que, se há apenas uma vontade de vida una e indivisa para além dos simples fenômenos, então teríamos "que aceitar a conclusão absurda de que a existência de um único indivíduo que consiga vencer toda e qualquer resistência e que com sua morte efetive a negação da Vontade poderia colocar fim a tudo que existe" (ANTONIASSI, Negação da vontade: a redenção na filosofia de Arthur Schopenhauer, p. 11).

18 MARCIN apud CARDOSO, A ideia de justiça em Schopenhauer, p. 117.
} 


\section{Inconsistências inerentes à tese da Justiça Eterna}

Pelo exposto, percebe-se que, ao menos aparentemente, há uma contradição entre a ideia de "justiça eterna" e aquilo que fora apresentado por nós relativamente à existência de um duplo significado de individualidade na filosofia de Schopenhauer, individuação corpórea e individualidade moral, pois esta última consiste em afirmar-se justamente naquilo que a "justiça eterna" nega: o caráter inteligível, que é individual, e que não é puro fenômeno sobmetido às formas do princípio de razão, possuindo, assim, autêntica raiz metafísica. Consequentemente, mesmo no âmbito do em si, teria de ser possível sustentar a manifestação de uma pluralidade de caracteres.

Porém, aqui surge um problema: se as duas teses são inconciliáveis, por que haveríamos de afirmar uma delas (individualidade moral), que se apoia em elementos um tanto obscuros e implícitos na filosofia de Schopenhauer, em detrimento da outra Justiça eterna), para a qual Schopenhauer dedicou um bom número de páginas e que parece surgir naturalmente a partir do ponto mais elementar de sua metafísica (a noção de vontade una e indivisa em todos os fenômenos)?

Passemos agora a expor dois argumentos pelos quais acreditamos poder justificar uma radical exclusão da "justiça eterna” do sistema filosófico de Schopenhauer, em benefício da tese da "individualidade moral” de raiz metafísica.

\section{A Justiça Eterna é autocontraditória}

A partir desta curta exposição, percebe-se algumas dificuldades. A primeira decorre da própria ideia de Justiça Eterna enquanto tese que prescinde da noção de individualidade. Pois para existir uma Justiça Eterna, que é na verdade a justificativa filosófica de Schopenhauer para todos os sofrimentos do mundo - inclusive para aqueles manifestamente injustos - é necessário supor que não só a culpa da vítima pelos atos de seu próprio agressor, mas também a culpa universal pelo sofrimento de cada um, e isto, conforme vimos, só é possível porque na esfera do em si não haveria nenhuma forma de individualidade.

Porém, é digno de nota o fato de que, para que sua teoria da Justiça Eterna faça algum sentido, Schopenhauer não deixa de recorrer a uma linguagem que, estranhamente, não nega a individualidade moral, mas afirma-a. Pois "em tudo o que acontece e pode acontecer a cada um, a justiça sempre lhe é feita, pois sua é a Vontade" (grifo nosso). O uso do pronome possessivo não é acidental, pois ele indica que a teoria só faz sentido se pressupormos que o indivíduo que sofre as penúrias do mundo, sofre-as com justiça apenas na medida em que ele próprio, indivíduo, é afirmador de sua vontade, da qual o mundo todo é mero espelho. Só há justiça eterna se este mundo, do qual sou um agente sofredor, é minha vontade. Em outras palavras, os sofrimentos deste mundo que se abatem sobre mim só se justificam porque eu escolhi viver nele, porque eu afirmei minha vontade (ainda que em uma dimensão transcendental). Não fosse assim, e se portanto relegássemos a individualidade moral à condição de simples ilusão - como aliás, repita-se, o próprio Schopenhauer faz diversas vezes - abrindo uma espécie de abismo entre individualidade e coisa-em-si, porque ausente qualquer dimensão ou elemento intermediário, o resultado seria uma compreensão segundo a qual apenas a Vontade impessoal afirma a si mesma, e os indivíduos não seriam afirmadores, mas uma espécie de objeto de afirmação desta "Vontade" terrível e cruel. Deste modo, a responsabilidade metafísica do indivíduo por sua própria condição (que é uma das premissas da justiça eterna) desapareceria, e a justiça eterna se converteria em injustiça eterna. Consequentemente, se Schopenhauer excluir de seu discurso todos os pronomes e frases que denotam particularidades e níveis de 
individuação (tais como "sua” e "nossa”), a teoria parece perder todo o sentido.

Portanto, para que a justiça eterna seja, afinal, justa, ela deve se referir a atores que afirmam suas vontades. Mas também sabemos, pela mesma teoria, que a vontade de cada um é a mesma que aparece em todas as coisas. Logo, o indivíduo é e não é esta vontade ao mesmo tempo, o que constitui uma contradição. Esta parece ser a base de toda a justiça eterna de Schopenhauer: uma contradição - que acreditamos refletir uma indecisão quanto às raízes metafísicas da individualidade humana.

Arriscamos dizer que, na melhor das hipóteses, a justiça eterna expressa não uma autocontradição, mas uma tensão entre elementos aparentemente contraditórios entre si, mas que na verdade se complementam. McAllister, explicando as teorias de Eric Voegelin sobre a con sciência, mostra-nos que a consciência humana não precisa ser necessariamente restrita à sua estrutura "intencional", que reduz nossa compreensão sobre o mundo sob a forma sujeito-objeto (traduzindo isso em termos schopenhauerianos, pode-se dizer que a "consciência intencional" fornece apenas representações) ${ }^{19}$. Superando a estrutura intencional, tem-se a estrutura "luminosa", que oferece "uma forma de cognição diferente daquela que diz respeito ao mundo físico" 20 , e que apreende a realidade em um nível muito mais profundo, a "realidade pretendida em seu modo de concretude" 21.

O problema que surge desta penetração da realidade é, em primeiro lugar, o fato de que a linguagem ou símbolos empregados para expressar aquilo que é apreendido pela consciência luminosa precisam deixar de ser "descritivos", para se tornarem meramente "exegéticos" 22 . Além disso, esta penetração ou "visão" conduz ao reconhecimento das "tensões” que compõem a estrutura imutável da realidade, tensões estas que se expressam na diferença entre o polo divino e o polo mundano da existência ${ }^{23}$. Estes polos são radicalmente diferentes, mas também irredutíveis entre si, e justamente porque fazem parte da estrutura da realidade. Deste modo, resta-nos a resignação pelo reconhecimento desta tensão inerente à realidade. Segundo McAllister, "só a pessoa cujo rigor espiritual é insuficiente para suportar a tensão, e cuja capacidade intelectual é suficiente para entendê-la, é capaz de produzir uma segunda realidade" 24 . Por "produzir uma segunda realidade" entenda-se aqui o desejo de negar um dos aspectos tensionais que constituem a realidade, para privilegiar apenas um deles. Exemplo disso são aqueles que negam o polo divino da existência, para afirmar apenas o polo mundano, e vice-versa.

Uma expressão particular desta tensão entre o polo divino e mundano é a tensão entre o uno e o múltiplo ${ }^{25}$. Ora, parece-nos que o discurso schopenhaueriano sobre a justiça eterna só pode ser justificado se entendido como situado nesta relação tensional (aparentemente contraditória e, por isso, insuportável para nossa "consciência intencional") entre a unidade metafísica da "Vontade" e a multiplicidade, também metafísica, de vontades. Sob este ponto de vista, é possível conjeturar que, sempre que Schopenhauer acomoda no mesmo discurso a ideia de justiça eterna baseada em uma vontade una e, ao mesmo tempo, na vontade de alguém, o resultado seria um equilíbrio tensional entre dois polos da estrutura da realidade. Nestas condições, a teoria pode ser melhor aceita. Mas sempre que Schopenhauer relega a multiplicidade de vontades à condição de "meras representações", "ilusões sob o véu de Maia”, etc., o que ele faz é tentar anular artificialmente um polo da existência para privilegiar o outro. O resultado

\footnotetext{
19 MCALLISTER, Revolta contra a modernidade, p. 349 e ss.

20 MCALLISTER, Revolta contra a modernidade, p. 350.

${ }^{21}$ VOEGELIN apud MCALLISTER, Revolta contra a modernidade, p. 349

22 MCALLISTER, Revolta contra a modernidade, p. 350.

${ }^{23}$ MCALLISTER, Revolta contra a modernidade, p. 178

24 MCALLISTER, Revolta contra a modernidadep. 175.

${ }^{25}$ MCALLISTER, Revolta contra a modernidade, p. 178.
} 
é um discurso mais claro que agrada nossa "consciência intencional”, mas que distorce a realidade. Cremos que esta "distorção da realidade”, embora agradável à nossa "consciência intencional", é radicalmente denunciada e rejeitada por nossa consciência moral, que corresponde, aproximadamente, à "consciência luminosa" descrita por McAllister a partir de Eric Voegelin (afinal, em termos schopenhauerianos a consciência moral está enraizada no polo metafísico da existência humana e, portanto, fundamenta-se em uma percepção que transcende a experiência física sob as formas do princípio de razão). E isto nos leva a uma segunda dificuldade envolvendo a teoria da justiça eterna.

\section{A justiça eterna é incompatível com o princípio metodológico de Schopenhauer}

Em diversos momentos de sua obra, Schopenhauer faz questão de frisar a importância de se adotar um método de investigação genuíno, sem o qual nenhuma filosofia pode cumprir sua tarefa, que é a de explicar a realidade. E este método, segundo Schopenhauer, só pode ser o "analítico". No §14 dos "fragmentos de história da filosofia", onde Schopenhauer expõe sua própria filosofia, ele escreve que "tudo o que fora aqui dito pode ser resumido no princípio segundo o qual minha filosofia forma-se e expõese pelo método analítico, e não pelo método sintético" (P I, Fragmente zur Geschichte der Philosophie, §14, p. 149). Este método é definido de forma clara por Schopenhauer nos suplementos ao Mundo como vontade e representação, no capítulo 12 ("sobre a doutrina da ciência" - zur Wissenschaftslehre) nos seguintes termos: "o método analítico tem por ponto de partida os fatos, o particular, para chegar às proposições, ao geral, ou parte das consequências para chegar aos fundamentos; o outro [sintético] faz o inverso" (W II, cap. 12, p. 143). Apesar de no mesmo escrito ele ridicularizar o ato de escolher o método antes de começar o ato de filosofar, isto não deve nos distrair quanto ao fato de que o próprio não só associava sua filosofia ao método analítico, mas em outros trechos de sua obra ele rejeita inteiramente qualquer outra maneira de filosofar que não seja aquela que parte do particular, do mundo intuído, para chegar às construções abstratas. Assim, no escrito Sobre a filosofia e seu método, ele é enfático ao dizer que a filosofia não poderia ser, como pensava Kant, "uma ciência a partir de meros conceitos", mas ", tal como a arte e a poesia, deve ter sua fonte na compreensão intuitiva do mundo" (P II, Ueber Philosophie und ihre Methode, $\$ 9$, p. 15). O mesmo é insistentemente repetido em seu escrito Sobre a educação (P II, cap. 28, p. 682 e ss.), e no mesmo espírito, escreve ele no início do quarto livro de $\mathrm{O}$ mundo como vontade e representação que "toda filosofia é sempre teórica, já que lhe é essencial manter uma atitude puramente contemplativa (...), e sempre inquirir, em vez de prescrever regras” (W I, §53, p. 353). Isso significa que sua Ética deve restringir-se à tentativa de explicação de nossas intuições morais, em lugar de prescrever uma nova moralidade ou de corrigir aquela já existente.

Com base em tudo isso, causa-nos estranheza sua própria admissão, no prefácio à primeira edição de Os dois problemas fundamentais da ética, sobre ter utilizado o método sintético no quarto livro de $\mathrm{O}$ mundo como vontade e representação, enquanto que naquela obra, ele procederia pelo método analítico (E, Vorrede zur ersten Auflage, p. 7). Ora, por que na investigação sobre a metafísica da natureza é necessário proceder pelo método analítico, enquanto que a metafísica dos costumes pode ser "deduzida sinteticamente e $a$ priori" (conforme as palavras do próprio Schopenhauer registradas no citado prefácio) de sua metafísica da natureza já constituída pelo método analítico?

O resultado desta confusão metodológica é evidente: nos dois livros que compõem Os dois problemas fundamentais da ética, onde todas as construções teóricas parecem simplesmente interpretar e expor fidedignamente nossas intuições morais, não seria possível concluir sobre uma “justiça eterna” consistente em afirmar que o mundo é em 
si mesmo justo; por outro lado, no quarto livro de O mundo como vontade e representação, onde o método sintético é empregado, deduz-se aquela suposta "justiça eterna” que, ao responsabilizar a vítima na mesma medida em que responsabiliza o agressor, nada mais faz do que contrariar todas as nossas intuições morais mais genuínas e elementares.

Deste modo, com a afirmação da tese da justiça eterna, Schopenhauer trai sua própria filosofia duplamente: primeiro, porque contraria flagrantemente seu próprio método filosófico que, aplicado à Ética, deveria limitar-se ao esclarecimento de nossas intuições morais já estabelecidas; e segundo, Schopenhauer substitui seu lúcido pessimismo por uma autêntica forma de otimismo, pois ao afirmar que "o mundo é o tribunal do mundo", que de um ponto de vista metafísico todos têm exatamente aquilo que merecem, etc., Schopenhauer exclui a possibilidade de qualquer injustiça do mundo. Isso significa que, para Schopenhauer, o mundo seria absolutamente justo, soando injusto apenas diante do frágil entendimento dos homens dominados pelo princípio de individuação. Em si, o mundo seria a autorrealização da mais completa e perfeita justiça! Apenas os tolos sonhadores sob o "véu de Maia” não conseguiriam percebê-lo... Parafraseando o próprio Schopenhauer ao acusar um eudemonismo implícito na filosofia de Kant (E II, II, §4, p. 28), poderíamos dizer que o "melhor dos mundos possíveis" leibniziano, que ele havia expulsado pela porta da frente de seu sistema, fora readmitido pela porta de trás, sob o nome de "justiça eterna".

\section{Conclusão}

Assim, na radical contradição existente entre, de um lado, a hipótese de uma individualidade de raiz metafísica e natureza moral, e de outro, a ideia de uma Justiça Eterna que se baseia na negação daquela mesma categoria de individuação, julgamos mais coerente afirmar a primeira em detrimento da última. Na verdade, a Justiça Eterna parece antes resultar de uma falha metodológica, ou melhor dizendo, de uma injustificável inversão metodológica operada pelo próprio Schopenhauer no livro IV de O mundo como vontade e representação. Não tivesse o filósofo frankfurtiano cometido esta inversão, e assim permanecido no sóbrio caminho oferecido pelo método analítico, ele não teria chegado a uma teoria que, em um primeiro momento, pareceu negar a si mesma, e em um segundo momento, contradiz flagrantemente nossas intuições morais mais lúcidas. Em contrapartida, a noção de individualidade moral mostra-se capaz de oferecer respostas a muitas aporias mais evidentes acusadas na Ética de Schopenhauer por seus estudiosos, conforme pensamos ter mostrado em estudo específico sobre o tema ${ }^{26}$.

Mas voltemos à justiça eterna. Relativamente ao problema de sua aparente autocontradição, acreditamos ter oferecido, a partir do pensamento de Voegelin, o esboço de uma possível alternativa através da noção de "consciência luminosa" e do discurso "exegético" que a acompanha, bem como da ideia de "tensões" inerentes à realidade que não são passíveis de resolução mediante superação dialética. Nestes termos, "justiça eterna” e "individualidade moral" poderiam coexistir em um mesmo sistema, pois não constituiriam propriamente uma contradição entre si, mas uma relação tensional. Porém, o preço a pagarmos pela sustentação deste estado de complementaridade é o abandono da clareza discursiva e a consequente adoção de um misticismo quase incomunicável. No entanto, deve-se reconhecer que esta alternativa talvez não seja tão alheia ao espírito do pensamento de Schopenhauer que, apesar de sua inclinação apolínea ao discurso lógico e construções sistemáticas, no entanto empreendeu uma filosofia que ousou encarar o abismo metafísico que constitui o âmago da existência e, por consequência disso, não raramente ultrapassou

${ }^{26}$ ORRUTEA FILHO, Sobre a distinção entre individualidade moral e individuação corpórea em Schopenhauer, p. 176 e ss. 
os limites da linguagem meramente descritiva, o que obrigou-o diversas vezes a recorrer ao uso de metáforas e de uma notável denominatio a potiori (W I, §22, p. 169).

Apesar desta possível manobra, ainda parece-nos que a Justiça Eterna falha miseravelmente em um ponto fundamental: ela simplesmente não parece explicar nossos juízos morais, e este é o grande objetivo da parte ética da filosofia de Schopenhauer. Deste modo, entre os elementos mais essenciais da obra de um filósofo - consistente no princípio metodológico que orienta seu filosofar bem como na finalidade para a qual se dirige sua filosofia - e as eventuais articulações verbais do mesmo, ainda que muito explícitas, preferimos conservar o primeiro, e excluir o último. Por este motivo, ousamos propor uma interpretação da metafísica da vontade que privilegie a noção de individualidade moral, enquanto recusa o dogma da Justiça Eterna.

\section{Referências}

ANTONIASSI, Ednilson. Negação da vontade: a redenção na filosofia de Arthur Schopenhauer. Trabalho apresentado durante os Encontros de Estudo do Núcleo de Pesquisa SchopenhauerNietzsche. No prelo, 2018.

CARDOSO, Renato César. A ideia de justiça em Schopenhauer. Belo Horizonte: Argvmentvm, 2008.

FERRAZ, Marília Côrtes de. Liberdade e responsabilidade moral em Schopenhauer. In: PAVÃO, A. et al (orgs). Schopenhauer: metafísica e moral. São Paulo: DWW Editorial, 2014.

HUSSERL, Edmund. A crise das ciências europeias e a fenomenologia transcendental. Tradução de Diogo Falcão Ferrer. Rio de Janeiro: Forense Universitária, 2012.

JANAWAY, Christopher. Schopenhauer. Tradução de Adail Ubirajara Sobral. São Paulo: Edições Loyola, 2003.

MAGEE, Brian. The philosophy of Schopenhauer. Revised and enlarged edition. New York: Oxford University Press, 2002.

MCALLISTER, Ted V. Revolta contra a modernidade: Leo Strauss, Eric Voegelin e a busca por uma ordem pós-liberal. Tradução de Túlio Sousa Borges de Oliveira. São Paulo: E Realizações, 2017.

PAVÃO, Aguinaldo. Liberdade e responsabilidade moral: o fracasso de Schopenhauer. Caderno de resumos do I Congresso do Núcleo de Pesquisa Schopenhauer-Nietzsche. Londrina: UEL, 2018.

ORRUTEA FILHO, Rogério Moreira. Sobre a distinção entre individualidade moral e individuação corpórea. In: PAVÃO, A. et al (orgs). Schopenhauer: metafísica e moral. São Paulo: DWW Editorial, 2014.

ROGER, Alain. Atualidade de Schopenhauer, in prefácio a Sobre o fundamento da moral. In: SCHOPENHAUER, Arthur. Sobre o fundamento da moral. Tradução de Maria Lúcia Mello Oliveira Cacciola. São Paulo: Martins Fontes, 2001.

SCHOPENHAUER, Arthur. Der handschriftlicher Nachlass, Band 4, 1: die Manuskriptbücher der Jahre 1830 - 1852. Ed. de Arthur Hübscher. München: DTV GmbH \& Co. KG.

SCHOPENHAUER, Arthur. Die beiden Grundprobleme der Ethik. Ed. de Arthur Hübscher. Zürich: Diogenes, 1977.

SCHOPENHAUER, Arthur. Die Welt als Wille und Vorstellung, zweiter Band. Ed. de Arthur Hübscher. Zürich: Diogenes, 1977.

SCHOPENHAUER, Arthur. Parerga und Paralipomena. erster Band. Ed. de Arthur Hübscher. Zürich: Diogenes, 1977.

SCHOPENHAUER, Arthur. Parerga und Paralipomena. zweiter Band. Ed. de Arthur Hübscher. Zürich: Diogenes, 1977. 
198 | Individualidade em sentido moral e justiça eterna

SCHOPENHAUER, Arthur. O mundo como vontade e como representação. Tradução de Jair Barboza. São Paulo: editora UNESP, 2005.

SCHOPENHAUER, Arthur. Sobre o fundamento da moral. Tradução de Maria Oliveira Cacciola. São Paulo: Martins Fontes, 2001.

SCHOPENHAUER, Arthur. Über den Willen in der Natur, Ed. de Arthur Hübscher. Zürich: Diogenes, 1977.

SCHOPENHAUER, Arthur. Über die vierfache Wurzel des Satzes vom zureichenden Grunde. Ed. de Arthur Hübscher. Zürich: Diogenes, 1977. 